\title{
IMPRENSA, MOVIMENTO DE MULHERES, FEMINISMO E VIOLÊNCIA DE GÊNERo no oEste do Paraná NAS DÉCADAS DE 1970 E 1980
}

\section{Tânia Regina Zimmermann ${ }^{1}$}

\begin{abstract}
Resumo
Este artigo tem por objetivo analisar algumas representações sobre o movimento de mulheres, feminismo e violência de gênero em diversos jornais impressos que circulavam na região Oeste do Paraná nas décadas de 1970 e 1980. Em relação a estes temas, esses veículos de comunicação entrecruzavam as relações de gênero e formas de violência contra e de mulheres. Os discursos em relação ao feminismo, em grande parte, eram ambíguos e relutavam entre o movimento da história e as mudanças nas relações de gênero. Assim, algumas permanências eram representadas como a submissão, resignação e bondade na construção do feminino, a violência como exclusividade masculina, além da aceitação da honra para justificar a violência contra as mulheres, presente em edições regionais sobre o caso Doca Street.
\end{abstract}

Palavras-chave: Imprensa. Feminismo. Violência. Relações de gênero.

\footnotetext{
${ }^{1}$ Professora do Departamento de História da Universidade Estadual do Mato Grosso do Sul, Unidade Universitária de Amambai. Doutoranda em História Cultural pela Universidade Federal de Santa Catarina. End. eletrônico: taniazimmermann@gmail.com
} 


\title{
THE NEWS MEDIA, THE WOMEN'S MOVEMENT, FEMINISM AND GENDER VIOLENCE IN WESTERn PaRANá IN THE 1970s AND 1980s
}

\begin{abstract}
This article analyzes some representations of the women's movement, feminism and gender violence in several newspapers that circulated in the western region of Paraná in the 1970s and 1980s. The material published on these themes also dealt with gender relations and forms of violence against women. The discourses on feminism were largely ambiguous and vacillated between the movement of history and changes in gender relations. Some aspects of continuity were represented as submission, resignation and goodness in the construction of the feminine; violence was understood as exclusively masculine; and the defense of honor was accepted to justify violence against women in the regional editions on the Doca Street case.
\end{abstract}

Keywords: Press. Feminism. Violence. Gender relations.

\section{INTRODUÇÃO}

$\mathrm{N}$

Teste artigo são analisadas algumas representações em notícias sobre o feminismo, movimento de mulheres², caso Doca Street e algumas aproximações com 0 tema da violência e crime sob uma perspectiva de gênero. As notícias sobre o feminismo e o movimento de mulheres reconheciam que direitos e conquistas para as mulheres estavam batendo à porta de lugares distantes de grandes centros do país. Mas a ênfase de grande parte dos escritos quer seja de colunas, artigos e entrevistas também recaia sobre os problemas advindos com a emancipação, como o divórcio, desarticulação das famílias e a criminalidade protagonizada por mulheres. Para tanto, se pretende enveredar pela imprensa do Oeste do Paraná entre as décadas de 1970 a 1980 para captar a ação de sujeitos sociais, especialmente de mulheres, que buscaram assumir as rédeas de suas vidas, sobretudo em relação à dominação masculina e formas de violência.

\footnotetext{
${ }^{2}$ Aqui são importantes os apontamentos de Joana Maria Pedro: "Entendo, como movimento feminista as lutas que reconhecem as mulheres como especificamentee sistematicamente oprimidas. É a afirmação de que as relações entre os homens e as mulheres não são inscritas na natureza, portanto, passíveis de transformação. Como movimento de mulheres, entendo movimentos cujas reivindicações não são de direitos específicos das mulheres. Trata-se de movimentos sociais cujos proponentes são, em sua maioria, mulheres" (2006, p. 270).
}

IMPRENSA, MOVIMENTO DE MULHERES, FEMINISMO E VIOLÊNCIA...

T. ZiMMERMANN $\bullet 163$ 


\section{MOVIMENTO DE MULHERES, FEMINISMO E VIOLÊNCIA eM notícias do Oeste Paranaense}

Como parte do processo histórico, jornais e revistas acompanharam no Oeste do Paraná com diversas reportagens, os movimentos feministas e de mulheres de outros países, do Brasil e da região. Especialmente no final da década de 1970 e na década de 1980, discussões sobre a condição feminina e encontros de mulheres na cidade de Toledo tornaram-se visíveis nos veículos impressos de comunicação. Uma das organizadoras destas discussões foi a socióloga e escritora Moema Viezzer ${ }^{3}$. Quando estabelecida no município de Toledo, atuou em grupos de base da cidade e comunidades rurais, objetivando promover a educação e a implementação de políticas públicas direcionadas para questões de gênero e meio ambiente. Na cidade de São Paulo, coordenou a Rede Mulher com diversas pesquisas sobre a participação popular e relações de gênero.

Em Toledo, Moema avaliou os grupos e clubes de mães existentes na periferia, tendo como intuito assessorá-los com palestras e encontros. Através de sua atuação, o Conselho da Condição Feminina no município de Toledo promoveu 0 I Encontro de Mulheres Toledanas em 1985. As discussões desse evento centraramse na elaboração de uma pauta sobre as condições de trabalho e remuneração, participação política, violência contra as mulheres e demanda de direitos, a ser entregue a constituintes em Brasília. A notícia abaixo ressaltava a presença de cerca de 500 mulheres nesse encontro e informa algumas de suas atividades:

Pela manhã as mulheres formaram cinco grupos de estudos para debater questões relacionadas a elas. Destes grupos saíram muitas resoluções, principalmente a respeito da violência contra as mulheres no lar e fora dele, suas condições de emprego e sua participação popular na vida política do país (CORREIO DO OESTE, 1985, p. 11).

Segundo o jornal Correio do Oeste, estas resoluções seriam encaminhadas ao Comitê Pró-Constituinte como forma de contribuição ao debate nacional em relação à elaboração de uma nova Constituição. Entre as palestrantes estava Moema Viezzer e Norma Kyriakos, sendo esta última procuradora geral, assessora

\footnotetext{
${ }^{3}$ Tribuna do Oeste. Moema Mulher. n. 246, 28 de março de 1981, p. 12. Segundo este jornal, Moema residiu na República Dominicana e Haiti e, no retorno ao Brasil, publicou vários livros. Se me deixam falar... Domitila é o relato de algumas experiências sobre participação popular de mulheres. Nesta obra, traduzida para 14 países, Moema condensa parte da história das duras condições de vida dos trabalhadores das minas de estanho na Bolívia, a partir de um relato de Domitila Barrios de Chungara, dirigente do Comitê das Donas de Casa do Século XX e esposa de um trabalhador da mina.
} 
especial do governo Franco Montoro e representante da Secretaria de Justiça do Estado de São Paulo. A notícia enfatizava a impressão positiva de Kyriakos sobre a ampla participação e mobilização de mulheres no interior do país: “ [...] isto é uma prova de que o Brasil é um país viável, mesmo porque um país que tem mulheres como estas aqui em Toledo, é viável mesmo. Cabe a nós transformá-lo" (CORREIO DO OESTE, 1985, p. 11). No Jornal do Oeste, o encontro é estampado na capa como $O$ Grande Encontro das Mulheres e no texto destaca-se o objetivo:

0 I Encontro de Mulheres Toledanas tem como objetivo discutir com as mulheres do município o atual contexto cultural-sócio-político e econômico do Brasil, como meio de possibilitar-lhes um crescimento dentro da estrutura, a caminho da plena realização feminina (JORNAL DO OESTE, 1985, p. 2).

Este encontro de mulheres manteve-se em notícias nos principais jornais de Toledo, sendo dado destaque pelo Jornal do Oeste: "A mulher está saindo da casca, está partindo para novas conquistas, e em Toledo, este processo está em andamento." (Idem, ibidem) No mesmo jornal, havia uma reportagem sobre a criação da Delegacia de Defesa da Mulher em algumas cidades do Brasil ${ }^{4}$. Segundo o texto, uma delegada do Estado do Espírito Santo expôs a situação de denúncia de estupro:

Nós tivemos três casos de estupro denunciados por vítimas, e isso pode representar que as mulheres aceitam a nova filosofia de tratamento dos crimes praticados contra elas. [...] Ela explicou que nos casos mais graves são instaurados inquéritos policiais e, até agora, três foram abertos e os agressores estão sendo processados (JORNAL DO OESTE, 1986, p.6).

Após a publicação dessas reportagens, das atividades de Moema em Toledo e das discussões sobre a violência de gênero ${ }^{5}$, nos anos subsequentes, o estupro começou a ser nomeado como violência sexual e não mais como anormalidade naquela cidade. Apesar disso, os jornais de outras cidades ${ }^{6}$ quando relatavam

\footnotetext{
${ }^{4} \mathrm{Na}$ região Oeste, a primeira Delegacia da Mulher foi criada em 7 de novembro de 1986 na cidade de Cascavel. 0 jornal 0 Paraná publica duas matérias sobre a sua instalação sob os títulos: "Delegacia da Mulher: Tina Ferraz vem para a instalação". n. 3136, 7 de novembro de 1986, p. 1 e "Violência contra a Mulher preocupa". n. 3156, 29 de novembro de 1986, p.3.

${ }^{5}$ Violência de gênero será aqui utilizada como o uso da força com ou sem instrumentos e simbólica, especialmente contra mulheres, mas também de mulheres contra homens, entre homens e entre mulheres.

${ }^{6}$ No jornal 0 Paraná, há menção do estupro como violência sexual, mas associado à anomalia: Violência Sexual: Gina morreu há 7 dias e anormais continuam soltos. n. 1222, 25 de junho de 1980. Jornal do Oeste. Violência Sexual: Jovem é violentada sob a mira de revólver. n. 195, 2 de abril de 1986, p. 6.
} 
ocorrências deste tipo, insistiam em considerá-las anomalias. Os títulos, frases e palavras nos jornais sobre essa modalidade de violência contra as mulheres revelavam a existência de um imaginário que levava, segundo Suarez, à seguinte avaliação do estupro:

[...] o estupro não era avaliado como crime e sim como monstruosidade, razão pela qual os agressores passam a ser percebidos mais como sujeitos marginais, carentes e poluentes do que propriamente transgressores (SUAREZ, 1999, p. 15).

Este imaginário para os atos de estupro estava presente na mídia do 0este do Paraná, como se constata a partir dos seguintes títulos: Matou anormal que violentou a filha; Anormais raptaram menor e tentaram seviciá-la; Tarado no Parque Verde?.

Além da publicidade das atividades coordenadas por Moema Viezzer, em Toledo, muitos dos jornais divulgavam reportagens, entrevistas e artigos sobre 0 feminismo e a emancipação das mulheres desde a década de 1970. Esta afirmação se pauta em títulos como: A civilização caminha para igualdade entre os sexos; A mulher brasileira é realizada?; Betty Friedan: menos passeatas e mais ação; Machismo: o fim de um reinado? Mulher: Falta de Liberdade e Marginalizada? Nem Feminismo nem Machismo: Justiça. A grande maioria desses artigos observava o feminismo como homogêneo, sendo uma tendência compreendê-lo como uma guerra entre os sexos na qual as mulheres feministas eram sexistas e se pautavam na possibilidade de dominação sobre os homens.

Segundo Perrot, o feminismo nem sempre gozou de boa reputação, pois muitas mulheres defendiam-se ao serem consideradas feministas. Para a autora, o feminismo deve ser visto como plural e variado e, num sentido amplo, como designação da luta pela igualdade entre homens e mulheres. Para Perrot, o feminismo age em movimentos súbitos, ou seja, por ondas. "É intermitente, sincopado, mas ressurgente, porque não se baseia em organizações estáveis capazes de capitalizá-lo" (PERROT, 2007, p. 155).

Esta luta pela igualdade entre os gêneros foi parte de um processo histórico em curso em vários países ocidentais. Luta esta advinda de movimentos sociais como o de mulheres, o feminista e o da contracultura que passou a ser denominada

\footnotetext{
${ }^{7}$ Sobre a construção de similitudes e diferenças entre o delinquente, monstro e tarado ver a tese de GAVRON, Eva. Dramas e Danos: Estudo de crimes sexuais na região de Florianópolis (1964-1985). Tese em História Cultural, Universidade Federal de Santa Catarina, 2008.
} 
de Revolução Cultural (HOBSBAWM, 1995) porque, em grande parte, focalizou as questões do corpo e da sexualidade. Neste contexto, o feminismo foi chamado de Segunda Onda, uma vez que difere da Primeira Onda dando prioridade às lutas pelo direito ao corpo, ao prazer e contra toda forma de dominação masculina, conhecida como patriarcado. Conforme Joana Pedro, uma das palavras de ordem da segunda onda era: o privado é político (PEDR0, 1995, p. 79). Segundo a autora, a Primeira Onda desenvolveu-se no final do século XIX e as lutas estavam centradas na reivindicação dos direitos políticos, sociais e econômicos, ou seja, no direito de votar e ser eleita, o trabalho remunerado, estudo, propriedade e herança.

Em relação à Segunda 0nda, estas lutas conquistavam espaço na mídia em vários países e, deste modo, nos jornais impressos regionais o tema não poderia passar sem divulgação e polêmicas. A batalha de palavras com foco nas mudanças nas relações de gênero era evidente em artigos, como este do jornal Fronteira do Iguaçu:

A Guerra Fria a qual nos referimos é a discosificação (sic) da mulher, a qual o homem alega que cada um tem que ficar no seu lugar. A mulher por sua vez, está querendo ganhar esta guerra, com armas as quais não se concatenam com sua essência. Esta essência, a qual nos referimos, são as armas que toda a mulher de bom senso pode usar, são elas: a meiguice, 0 charme, a feminilidade. Entretanto, não devemos esquecer que cada sexo tem seu lugar neste mundo chamado terra. Não vamos conseguir a nossa emancipação através de prensas na parede do outro sexo. Sejamos iguais, sejamos equilibrados, sejamos nós mesmas, vamos largar deste complexo de inferioridade em relação ao homem. Talvez no fundo eles saibam que nós não somos inferiores a eles (FRONTEIRA DO IGUAÇU, 1972, p. 6).

Neste artigo, acreditava-se na existência de uma essência feminina para as mulheres, assim como numa oposição binária natural entre os sexos, porém admitia-se que mudanças estavam ocorrendo em relação à divisão de trabalho entre mulheres e homens. No excerto abaixo, a emancipação era uma questão de conquista lenta pautada na essência feminina:

Por isso achamos que é muito melhor conseguirmos ao mesmo tempo a nossa emancipação calmamente e sermos consideradas como mulheres agindo de tal forma que conceba chamarmos mulheres, do que conseguirmos esta, imediata, mas sermos consideradas masculinizadas como Betti Friedan (sic) (Idem, ibidem). 
Após a segunda metade da década de 1970, diminuem as críticas dos jornais em relação às possibilidades de acesso de mulheres às carreiras consideradas masculinas 8 , mas elas deveriam permanecer em atividades e atitudes relacionadas ao espaço privado como a maternidade, educação dos filhos, delicadeza, contenção, discrição, passividade e meiguice. Neste sentido, são elucidativos os estudos de Hirata e Kergoat ao analisarem que a divisão sexual do trabalho em países ocidentais, na Europa e na América do Norte contribuiu para as desigualdades e conflitos de gênero na medida em que se naturalizava a incumbência simultânea da responsabilidade profissional e familiar às mulheres (HIRATA; KERGOAT, 2007). 0 artigo Conquistas da mulher resultam também no acúmulo de funções corrobora nesta questão ao entender que mulheres que trabalhavam em empregos remunerados deveriam acumular funções, pois “[...] 0 homem ao voltar para casa já cumpriu sua parte” (0 PARANÁ, 1989, p. 4).

Para grande parte de artigos e reportagens e entrevistas produzidas com mulheres empresárias, jornalistas e professoras, a emancipação era considerada uma conquista individual, como releva 0 artigo assinado por Maristela A. Belinho:

Hoje, mais e mais as mulheres se apercebem que as tarefas do lar e junto à família não é tudo, mas algo que juntamente com outras coisas pode vir a realizá-la. [...] 0 principal não é ter uma profissão, mas ser respeitada enquanto indivíduo, conquistar um lugar ao lado do homem (0 PARANÁ, 1986, p. 4).

Belinho entendia essa conquista como a busca por informações políticas, econômicas, culturais, sobre si mesma, bem como a discussão destas questões com o marido, de modo que contribuem para sua autoestima, mesmo permanecendo nas tarefas do lar. Em entrevista publicada no mesmo jornal, Maria Tereza Lazari também compreendia a emancipação feminina como uma conquista individual, mas acrescentava a necessidade da profissionalização da mulher e da divisão das tarefas no lar: "Não existe mais aquela idéia do lar como um museu. Além disso, a tecnologia ajuda muito" (0 PARANÁ, 1976, p. 7). Lazari, ao se referir aos movimentos feministas, observava sua importância na conscientização da mulher sobre sua própria capacidade, mas fazia questão de ressaltar:

[...] não tem nada contra os homens e eu os admiro pelo seu trabalho e inteligência e por terem durante tanto tempo aceito o encargo de dirigirem sozinhos os destinos da família e da sociedade (Idem, ibidem).

${ }^{8} 0$ Paraná. A presença da Mulher na carreira jurídica. n. 3144, 16 de novembro de 1986, p.3. Mulheres também atuando na Medicina Veterinária. n. 1640, 1 de dezembro de 1981. p. 12. 
Em outro artigo, Maria do Roccio dos Santos Junqueira posicionava-se contra os movimentos feministas e a igualdade:

[...] toda a mulher deve ter seu lugar na sociedade, pois nós temos capacidade.

[...] Igualdade é bobagem. Os Homens e as Mulheres devem andar juntos, cada um desenvolvendo suas potencialidades. [...] A mulher precisa e deve conservar sua feminilidade (0 PARANÁ, 1976, p. 6).

Também se dava publicidade a uma campanha contra o feminismo através de títulos bombásticos em artigos como estes: Quando uma feminista gosta de homens e Feminismo ataca as freiras. Neste último artigo, um professor da Universidade de Siena observava uma crise vocacional, mas sem menção ao feminismo e sim ao reduzido número de estudantes de teologia (0 PARANÁ, 1976, p. 12).

Outros artigos, com menor destaque, são esclarecedores sobre o feminismo e sua história. No artigo Feminismo apresenta-se um resumo desde a atuação dos clubes femininos de Atenas e as datas históricas relevantes para o feminismo até a década de 1970. No texto A evolução feminina, segundo as feministas, estudantes e professoras de história e sociologia da Universidade de Pádua, Itália, mostram, sob a forma de histórias em quadrinhos, experiências de vida livre e independente de mulheres na Grécia Antiga, entre povos bárbaros, na idade média européia, e a construção de formas de dominação masculina, principalmente após o século XV (0 PARANÁ, 1977, p. 13).

0 artigo sob o título Elas querem derrubar a ditadura do bomem apresenta um protesto de mulheres que tomaram escritórios de editoras de livros e filmes eróticos em Nova Iorque. Neste texto, o movimento feminista aparece como plural e focaliza a luta das mulheres por igualdade salarial e contra a exploração do corpo feminino em filmes, livros, revistas e publicidade (0 PARANÁ, 1979, p. 13).

A Mulher tem cabeça? É um título de um artigo que chama a atenção do leitor ao observar dados da biologia sobre as medidas do crânio de homens e mulheres e desconstrói a ideia de uma natureza feminina como mais emotiva, instável e irracional. Com dados de pesquisadores de anatomia e das ciências humanas, concluiu-se que não existia diferenciação nas faculdades mentais em relação ao peso dos cérebros quer seja de homens ou de mulheres. Segundo este artigo, os estudos apontavam também que os distúrbios psíquicos de mulheres estavam relacionados com seu papel feminino tradicionalmente adquirido (0 PARANÁ, 1977, p. 10). 
Embora estes quatro últimos artigos dêem visibilidade à pluralidade de ações de feministas, em grande parte dos textos entende-se o feminismo como a causa de inúmeros problemas, como a destruição da família, dos costumes, a legalização do divórcio e do aborto e a escalada de mulheres em atividades ilícitas. 0 artigo a seguir relaciona o feminismo com 0 aumento da criminalidade de mulheres. Para tanto se remete à realidade nos Estados Unidos:

A criminalidade feminina se incrementa consideravelmente nos Estados Unidos em razão, segundo algumas opiniões, do crescente desenvolvimento dos movimentos de libertação da mulher. Este é 0 ano Internacional da Mulher segundo a ONU (FRONTEIRA DO IGUAÇU, 1975, p. 3).

Ainda segundo este artigo, de acordo com o FBI (Federal Bureau of Investigation), no período de 1960-1973, o índice de detenção por delitos graves como homicídio, ataques à mão armada e roubo com agressão teria aumentado $277,9 \%$ entre as mulheres contra 87,9\% entre os homens. Sugere-se então entender a estreita relação entre a escalada da delinquência feminina e o Movimento de Libertação da Mulher com estudos aprofundados sobre o fenômeno: As mulheres não querem mais ser cidadão de segunda categoria na sociedade. 0 artigo menciona um estudo de Freda Adler, dado que ela relaciona o feminismo com 0 aumento da criminalidade feminina nos Estados Unidos. 0 texto do jornal corrobora com a assertiva de que os delitos estão relacionados a uma nova qualificação dos atos cometidos por mulheres:

Os principais delitos cometidos por mulheres eram, até há pouco tempo, a prostituição e o furto nos supermercados. Mas, nestes últimos anos as mulheres delinqüentes preferem as falsificações, fraudes e delitos desta espécie. Segundo o FBI, as detenções por falsificações do período 69-73 cresceram em 116,8\% contra apenas 15,3\% entre os homens (Idem, ibidem).

Este artigo poderia levar o leitor a concluir que as estatísticas do FBI falavam por si como uma verdade estabelecida. Assim, as motivações para os crimes de mulheres, de acordo com este jornal, foram indiretamente relacionadas com os movimentos emancipatórios feministas e também articulados ao conjunto de mudanças sobre determinados valores relacionados à família e às funções da mulher-mãe.

Segundo estudos de Soyka, nos últimos vinte anos do século XX, estes valores em fluidez de fato aumentaram a participação de mulheres mais jovens na criminalidade, até pouco tempo considerada como coisa de homem na Europa. Paradoxalmente, segundo este autor, os crimes que envolviam assassinatos 
cometidos por mulheres diminuíram, pois as discussões sobre as relações de gênero e a autonomia feminina possibilitaram a resolução destes conflitos de outras formas (SOYKA, 2005, p. 5). Todavia, este estudo recente de Soyka e o de Freda Adler dos anos de 1970, em sua obra Sisters in Crime, não levaram em conta as motivações econômicas, de classe, de geração e étnicas presentes em países desenvolvidos e em desenvolvimento9. Estas questões também são importantes nos estudos sobre o envolvimento das mulheres em crimes, entretanto, pouco foram consideradas em notícias. Por fim, este mesmo artigo, ao explorar a noção do aumento da criminalidade feminina e o feminismo, continua a campanha para manter as mulheres na subserviência e nas atividades do lar.

Pelo modelo predominante de família patriarcal presente nos discursos dos jornais, bem como pelos atributos femininos e sua associação com o mal, ao desvio, à desordem e a fraqueza moral, é que a violência contra as mulheres se instaura pela cultura. Isto está bem presente nas representações sobre os assassinatos de mulheres. Embora o movimento feminista da Segunda Onda colocasse em pauta novas possibilidades para as mulheres, como o direito sobre o seu corpo e sobre a punição em relação às violações dos mesmos, muitos assassinatos de mulheres ainda eram justificados como crimes passionais e de honra. No Brasil, o caso Doca Street ganhou manchetes nacionais, internacionais e locais, a ponto de reabrir 0 debate sobre os crimes passionais. Para as feministas, a violência contra as mulheres era considerada como mais um dos graves problemas na sociedade (PINTO, 2003, p. 80). Em grande parte das notícias sobre Doca Street, na imprensa do Oeste do Paraná, destaca-se um protagonista atordoado pela paixão ao cometer o crime. Esse conjunto de notícias sobre o crime, o criminoso, a vítima, o julgamento e a prisão tornou-se um emaranhado de jogos estratégicos que envolvia a dominação masculina.

\section{IMPRENSA E VIOLÊNCIA CONTRA MULHERES: CASO Doca STREeT NOS JORNAIS DA região Oeste do Paraná}

Raul Fernando do Amaral Street foi o autor de um dos crimes de maior repercussão nas últimas décadas do século passado no Brasil. 0 desfecho do caso foi considerado símbolo do machismo devido a sua absolvição em virtude do

${ }^{9}$ Consultar Adler (2003). 
argumento em defesa da honra. A jurisprudência nacional do período cunhou 0 direito ao homem de matar pela honra. Ao alegar traição, o crime deixava de existir como tal. A eliminação da mulher era um direito legitimado. 0 crime em questão ocorreu em Cabo Frio, no Rio de Janeiro, em 30 de dezembro de 1976.

0 crime deixou de ser um caso policial e virou símbolo da luta das mulheres pela punição dos homens violentos. A absolvição do criminoso provocou uma das primeiras grandes campanhas públicas das feministas no país contra a violência. 0 movimento feminista polemizou que a violência contra as mulheres, além de ser de grandes proporções, era invisível (SUAREZ; BANDEIRA, 1999, p. 15). Essa luta pelo fim da violência contra as mulheres elevou um grito pelo país: quem ama não mata! A partir de então um amplo e diversificado movimento feminista empenhou-se na luta pela vida sem sofrimento para as mulheres.

Os atos de violência contra as mulheres revelavam que brutalizar, violentar e/ou matar eram ações praticadas por companheiros ou ex-companheiros, pais, policiais e outros homens. Vários estudos na década de 1980, como de Mariza Correa (1981, 1983), Rachel Soihet (1989) e Maria Amélia Azevedo (1985), acentuam as denúncias da violência contra as mulheres. A partir destas denúncias, alavancaram-se estudos significativos sobre o tema à luz de categorias como gênero, a partir de uma perspectiva relacional sob olhares intersubjetivos dos envolvidos em situação de violência. 0 assassinato de Ângela Maria Fernades Diniz e a mobilização de mulheres pela punição de Doca certamente contribuíram para avanços na demanda dos direitos das mulheres a uma vida sem violência (GROSSI, 1993).

Mas como foram representados o crime, criminoso, vítima e movimentos de mulheres relacionados ao caso? Nos jornais do Oeste, são marcantes as atenções dadas ao crime de Doca Strett, cujos desdobramentos são traçados do ato do crime à primeira saída da prisão. Os fatos do crime começam a ser narrados a partir de 1976, especialmente no jornal O Paraná. Para este veículo de comunicação, o crime tem "[...] todos os ingredientes para se tornar um dos crimes passionais mais comentados dos últimos tempos" (0 PARANÁ, 1976, p. 1). Na notícia, supôs-se tratar de um triângulo amoroso e testemunhas poderiam descrever as cenas de ciúmes do criminoso. A versão da empregada é uma das únicas a apontar que Doca explorava Ângela financeiramente, era violento e coagia a vítima (Idem, p. 7). 
Posteriormente, em outras edições, os jornais regionais ocupavam-se sobremaneira em descobrir algum desvio no comportamento de Ângela Diniz que a culpasse pelo estado psicológico de Doca. Destarte, um médico psiquiatra expôs o quadro clínico do criminoso: coma alcoólico e depressão, agitação psicomotora quando ansioso e ideias de suicídio. Além disso, sugere a notícia que o relaxamento da prisão iria ocorrer com ampla documentação, incluindo declarações de industriais e empresários de São Paulo a respeito da vida pregressa do acusado. A partir do depoimento de um amigo comerciante, os argumentos em favor de Doca são assim descritos: "[...], pois desde criança [...] pessoa de temperamento calmo, de ótimos sentimentos e não me lembro de ter-se envolvido em atos de violência ou agressivos e que tampouco andasse armado" (Idem, 1977, p. 16). Neste depoimento, o comerciante expôs a situação financeira de Doca antes de seus casamentos e de que este não dispunha de grandes recursos financeiros, assim como, nas separações, não fazia exigências de ordem patrimonial. Este comerciante ressalta ainda que era Ângela quem teria forçado a separação de Doca com a ex-mulher (Idem, ibidem).

De acordo com Blay, a partir do depoimento do amigo de Doca Street, a defesa construiu duas imagens do acusado. Primeiro, era preciso demonstrar o bom caráter do assassino desde a infância. Segundo, era necessário caracterizar a vítima como motivadora do crime (BLAY, 2003, p. 90). Assim, Evandro Lins e Silva, advogado de defesa, ressaltou os sentimentos que levaram Doca a cometer 0 crime. Para captar estas emoções, serviu-se da literatura, especialmente da obra $A$ Servidão Humana, para entender a rejeição sentida pelos amantes. De tal modo, Silva utilizou-se dos sentimentos de rejeição, paixão e desvario para comover o júri e inocentar o ato contra a mulher amada que pecou ao não aceitar o amor de Doca.

Em relação à rejeição, mas sob a perspectiva da potência e da impotência, Saffioti (2004) acrescenta que Doca Street descarregou seu revólver especialmente no rosto de Ângela, pois “[...] atirar num lindo rosto deve ter tido um significado, talvez o fato de aquela grande beleza tê-lo fascinado, aprisionado-o a ela, impotente para abandoná-la"10. Para a autora, Doca estava inconformado com a decisão de Ângela em romper definitivamente a relação amorosa e com o seu insucesso na tentativa de persuadi-la a reconsiderar a decisão, sendo assim, assassinou-a.

\footnotetext{
${ }^{10}$ Para esta autora, as mulheres estão familiarizadas com a impotência, mas não é o caso dos homens que ao perpetrar a violência acreditam que estão sob o seu efeito.
} 
Segundo a notícia, “[...] uma pessoa correta como Doca só pode pela paixão cometer tal crime" (0 PARANÁ, 1977, p. 16). Blay conclui que nenhum tipo de sentimento pode justificar a morte e a perda de direitos humanos de mulheres, homens de diferentes classes, grupos étnicos e de demais minorias (BLAY, 2003, p. 90).

Uma notícia sobre o primeiro julgamento comemorava a absolvição de Doca Street: No Rio Doca é liberado. Apesar de ter sido condenado a dois anos de prisão, Doca não precisaria cumpri-la por ser réu primário, frente a isso, o jornal evoca a vitória da defesa. Na ocasião, o juiz concedeu-lhe o direito a sursis, ou seja, o réu é condenado, mas não cumpre a pena de privação de liberdade. 0 jornal ainda expôs parte da fala da entrevista concedida por Doca a jornalistas: "Gostei da decisão dos jurados. Foi o melhor momento da minha vida. [...] apesar de ser católico não fiz nenhuma promessa" (0 PARANÁ, 1979), p. 6). Segue no jornal que 250 pessoas aguardavam do lado de fora com cartazes apoiando o acusado. 0 primeiro julgamento foi anulado pelo Tribunal de Justiça do Estado do Rio de Janeiro. Um grupo de feministas organizou-se para conscientizar a população de Cabo Frio, de onde sairiam os jurados que integrariam o conselho de sentença do segundo julgamento. (SAFFIOTI, 2004, p. 51) A pressão de movimentos feministas também se fez sentir por meio de protestos quanto à decisão do primeiro julgamento. Como um rastilho de pólvora, eles se espalharam pelo Brasil afora e, certamente, pesaram no momento da anulação da sentença proferida na primeira instância.

Diversas edições do jornal 0 Paraná acompanharam o primeiro e segundo julgamento sem assinalar a pressão de movimentos feministas sobre o caso. Apenas uma notícia expôs que manifestações estavam proibidas no segundo julgamento de Doca. Nessa notícia, ainda apresentava-se a necessidade de segurança do Fórum e o fato de que, no primeiro julgamento, Doca saiu aplaudido como ídolo e herói. A notícia ainda reforçava: "No Fórum, a impressão é de que a legítima defesa da honra criada pelo mineiro Pedro Aleixo, comovera tanto os jurados quanto no julgamento anterior de Doca" (0 PARANÁ, 1981, p. 1).

No jornal O Paraná, há detalhes da defesa no segundo julgamento: “[...] insensato garotão apaixonado por Ângela e que matou por amor" (0 PARANÁ, 1981, p. 1). E a notícia continuava na defesa do criminoso: "Dos quinze anos de prisão por ser réu primário pode sair do julgamento em liberdade e segundo 0 juiz nada assegurara que Doca não fugira, pois não ficara sob vigilância policial 
mas poderia fugir se quisesse". Conforme lembra Blay, em nome da ampla defesa dos réus, certos aplicadores do direito subestimavam a violência praticada contra mulheres. Blay também alerta para a facilidade com que os procedimentos judiciais permitiam a fuga dos réus (BLAY, 2003, p. 96) .

Concomitantemente ao período em que Doca Street é julgado, outro fato importante tem lugar no cenário nacional: a campanha feminista nacional contra a violência em relação às mulheres. 0 jornal 0 Paraná e os demais silenciaram sobre a campanha que repudiava publicamente 0 amor como justificativa para 0 crime no país. Também a imprensa regional situava-se na defesa do acusado e, em nenhuma notícia, discutia-se a participação de feministas pela condenação de Doca. As manifestações apresentadas por este jornal colocavam-se a favor do criminoso. Segundo Blay, parte da imprensa paulista revelava indignação contra as feministas e suas manifestações públicas, as quais, segundo esta imprensa, pré-condenaram o réu. Esta autora ainda observa que para alguns jornalistas, uma simples briga entre amantes dificilmente poderia se transformar em acontecimento nacional. Tratava-se de um incidente como se a vítima ainda estivesse viva. Conforme lembra Blay, o defensor de Doca revelou seu espanto ante a extraordinária pressão popular que acompanhou o julgamento. O Paraná apenas menciona que a defesa e a acusação atuavam como se o julgamento fosse um circo, ora conduzido pela defesa e ora pela acusação com risos e aplausos da plateia (0 PARANÁ, 1979, p. 6).

$\mathrm{Na}$ imprensa regional, paralelamente às notícias sobre o caso Doca Street, casos de violência contra mulheres ganhavam destaque. Em grande parte destes textos, os motivos dos crimes ainda eram condicionados a ciúmes e ganância, sendo a culpa, normalmente, atribuída à conduta da mulher. Nas notícias, os crimes considerados passionais e de honra eram continuamente romantizados e dramatizados, além de haver um incremento na representação da violência com tais justificativas.

Para o movimento de mulheres e o feminismo, o tema aglutinador no Brasil dos anos de 1970 e no Oeste do Paraná na década de 1980 foi a violência contra as mulheres, ou seja, o direito a uma vida digna, a possibilidade de denunciar as situações de violência e da criação de leis e de instituições públicas capazes de atende-las. 0 movimento histórico engendrado por mulheres na região e a atuação de Moema Viezzer abriu a possibilidade do não conformismo e de enfrentamento contra as situações de violência e violações de direitos frente 
às insurgências de feministas no Brasil geradas a partir do caso Doca Street. Os crimes passionais, a violência sexual assim como outras violações nos revelavam que nenhuma forma de sofrimento e violência poderia ser justificada por situações étnicas, econômicas e, sobretudo, de gênero.

Em relação às situações de violência perpetrada por mulheres em âmbito internacional, especialmente em países europeus e nos Estados Unidos da década de 1970, o movimento feminista levava o peso das críticas sobre o aumento da criminalidade feminina. Esse aumento, para Adler (1975), devia-se às maiores possibilidades das mulheres adentrarem ao mundo antes exclusivo dos homens, ou seja, nos furtos, assaltos e homicídios. Mesmo com as críticas, movimentos como o feminismo neste período não tinham como demanda estas situações de violências, uma vez que se levava em conta a mulher como vítima pelas proporções e silêncios em que eram violados os direitos das mulheres. Estas lutas feministas, em processo contínuo, abririam posteriormente discussões para toda e qualquer forma de violência bem como na expansão da ideia de crime.

\section{REFERÊNCIAS}

ADLER, Freda. Sisters in crime: the rise of the new female criminal. New York: Mc Graw-Hill, 1975.

. A feminist perspective on women and crime. In: Kelta Advanced

Learning, 2003. Disponível em: http://www.keltawebconcepts.com.au/efemcrim1. htm Acesso em 17 de junho de 2009.

AZEVED0. Maria Amélia. Mulheres espancadas: a violência denunciada. São Paulo: Cortez, 1985.

BLAY, Eva Altman. Violência contra a mulher e políticas públicas. Estudos Avançados, São Paulo, n. 17 (49), 2003, p. 87-98.

CORRÊA, Mariza. Morte em familia. Rio de Janeiro: Graal, 1983.

. Crimes da paixão. São Paulo: Brasiliense, 1981.

GAVRON, Eva. Dramas e danos: estudo de crimes sexuais na região de Florianópolis (1964-1985). Tese em História Cultural, Universidade Federal de Santa Catarina, 2008. 
GROSSI, Miriam Pillar. De Ângela Diniz a Daniela Perez: a trajetória da impunidade. Revista de Estudos Feministas, Rio de Janeiro, n. 1, 1993, p. 156-168.

HIRATA, Helena; KERGOAT, Danièle. Novas configurações da divisão sexual do trabalho. Cadernos de Pesquisa, São Paulo, vol. 37, n. 132, set/dez 2007, p. 595609 .

HOBSBAWM, Eric. Era dos Extremos: o breve século XX 1914-1991. São Paulo : Companhia das Letras. 1995.

KELTA ADVANCE LEARNING. A feminist perspective on women and crime. Disponível em: <http://www.Keltawebconcepts.com.au>. Acesso em 17 de junho de 2009.

PEDRO, Joana Maria. Traduzindo o debate: o uso da categoria gênero na pesquisa histórica. Revista História, São Paulo, vol. 24, n.1, 2005, p. 77-98.

PERROT. Michelle. Minha história das mulheres. São Paulo: Contexto, 2007.

PINTO, Celi Regina Jardim. Uma história do feminismo no Brasil. São Paulo: Perseu Abramo, 2003.

SAFFIOTI, Heleieth. Gênero, patriarcado e violência. São Paulo: Perseu Abramo, 2004.

SOYKA, Michael. Wenn Frauen töten. New York, Stuttgart: Schattauer, 2005.

SOIHET, Rachel. Condição feminina e formas de violência. Rio de Janeiro: Forense Universitária, 1989.

SUÁREZ, Mireya; BANDEIRA, Lourdes. Violência, gênero e crime no Distrito Federal. Brasília: UnB, 1999. 